\title{
Effect of Intensive Education and Training of Nurses on Ventilator-associated Pneumonia and Central Line-associated Bloodstream Infection Incidence in Intensive Care Unit at a Tertiary Care Center in North India
}

\author{
Neeru Sahni, Manisha Biswal' ${ }^{1}$, Komal Gandhi, Kulbeer Kaur², Vikas Saini, Lakshminarayana N. Yaddanapudi \\ Departments of Anaesthesia and Intensive Care and ${ }^{~ M e d i c a l ~ M i c r o b i o l o g y, ~ P o s t g r a d u a t e ~ I n s t i t u t e ~ o f ~ M e d i c a l ~ E d u c a t i o n ~ a n d ~ R e s e a r c h, ~}{ }^{2}$ Division of Infection Control, \\ Postgraduate Institute of Medical Education and Research, Chandigarh, India
}

\section{Abstract}

Objective: The aim was to analyze the impact of education and training of nurses on the incidence of ventilator-associated pneumonia (VAP) and central line-associated bloodstream infection (CLABSI). Patients and Methods: A prospective observational study at a tertiary care hospital included adult patients with Intensive Care Unit stay $>48 \mathrm{~h}$. The study was done in three phases: in Phase 1, baseline VAP and CLABSI incidence was calculated; in Phase 2, education and training of nurses; and in Phase 3, data were recollected for the incidence of VAP and CLABSI. Results: The baseline incidence of VAP in Phase 1 was 28.86/1000 ventilator days and that of CLABSI was 7.89/1000 central-line days. In Phase 3, the incidence of VAP increased to 35.06 and that of CLABSI decreased significantly, 1.73. Conclusion: Intensive education and training sessions with feedback from nurses over a period of 6 months led to significant reduction in the incidence of CLABSI; however, the incidence of VAP increased.

Keywords: Intensive Care Unit, nurses training, patient care bundles, ventilator-associated pneumonia

\section{INTRODUCTION}

Central line-associated bloodstream infection (CLABSI) and ventilator-associated pneumonia (VAP) are two major causes of secondary sepsis in critically ill patients responsible for worsening of clinical condition of patients despite initial response to primary disease process leading to Intensive Care Unit (ICU) admission. ${ }^{[1]}$ The secondary sepsis in an already critically ill patient with multidrug-resistant flora of ICU leads to significant morbidity and even mortality. The cost of treatment increases exponentially due to the requirement of higher antibiotics and support system required in view of multiorgan dysfunction which sets in. ${ }^{[1]}$ The old dictum of "prevention is better than cure" is probably true in ICU setting more than anywhere else. As nursing staffs are the backbone of any ICU and come in patient contact more than anyone else, their education and knowledge of practices to prevent secondary sepsis is of utmost importance. ${ }^{[2]}$

\begin{tabular}{|l|l|}
\hline \multicolumn{2}{|c|}{ Access this article online } \\
\hline Quick Response Code: & Website: \\
\hline & www.ijccm.org \\
\hline
\end{tabular}

The aim of our study was to establish baseline VAP and CLABSI incidence, to intervene by education, training, and feedback from nurses, and to analyze its impact on the incidence of VAP and CLABSI in postintervention phase.

\section{Patients and Methods}

After approval from the Institute Ethics committee (NK/2466/ Study/2816), the study was done in ICU of our institute. Our ICU is a 12-bedded adult ICU which admits mainly medical patients along with few surgical and obstetric patients. The data of all adult patients admitted in ICU with an ICU stay

Address for correspondence: Dr. Neeru Sahni, Department of Anaesthesia and Intensive Care, Postgraduate Institute of Medical Education and Research, Chandigarh - 160 012, India. E-mail: neerunalin@yahoo.com

This is an open access article distributed under the terms of the Creative Commons Attribution-NonCommercial-ShareAlike 3.0 License, which allows others to remix, tweak, and build upon the work non-commercially, as long as the author is credited and the new creations are licensed under the identical terms.

For reprints contact: reprints@medknow.com

How to cite this article: Sahni N, Biswal M, Gandhi K, Kaur K, Saini V, Yaddanapudi LN. Effect of intensive education and training of nurses on ventilator-associated pneumonia and central line-associated bloodstream infection incidence in intensive care unit at a tertiary care center in North India. Indian J Crit Care Med 2017;21:779-82. 
of $>48 \mathrm{~h}$ were analyzed for the purpose of study. The patients whose ICU stay was $<48 \mathrm{~h}$ were not included for the purpose of data collection.

The demographic data and other parameters considered as possible risk factors such as age, gender, the presence of underlying diseases or comorbid conditions, APACHE II at $24 \mathrm{~h}$, days of central venous cannulation, and number of ventilator days were recorded for the purpose of comparison between the patient characteristics in pre- and postintervention phase.

The study was carried out in three phases. In Phase 1 (preintervention) (April-September 2015), baseline VAP and CLABSI incidence was calculated. All patients were monitored for CLABSI and VAP after ICU admission by clinical and microbiology standards according to the Centers for Disease Control and Prevention criteria. VAP and CLABSI rates were calculated using 1000 device days as a denominator. Phase 2 (intervention) (October 2015-March 2016) consisted of education and training of nurses by a team of doctors and infection control nurse. This included didactic lectures, PowerPoint presentation, and bedside teaching, one each day in small groups so as to have active participation from the staff nurses attending these sessions. Emphasis was laid on hand hygiene, VAP bundles, and CLABSI bundles and the hurdles faced in following these were discussed with the staff nurses. A record was kept to ensure attendance of all nurses in the classes and bedside trainings conducted, at least once each for hand hygiene, VAP, and CLABSI bundles. Regular audits on hand hygiene and bundle compliance were then conducted, and the feedback was given to all the staffs on a regular basis. The nurses were also asked to fill a questionnaire anonymously for feedback on classes and training sessions [Annexure 1]. In Phase 3 (April-September 2016), data were recollected for the incidence of VAP and CLABSI to see the impact of education, training, and bedside interaction with nursing staff on the overall incidence of VAP and CLABSI in ICU. The difference between VAP and CLABSI incidence in pre- and postintervention phase every month was compared using Student's $t$-test.

\section{RESULTS}

Our ICU is a 12-bedded unit with nurse-to-patient ratio of $2: 3$. The nurses work in three shifts, morning shift of $6 \mathrm{~h}$, evening of $6 \mathrm{~h}$, and night shift of $12 \mathrm{~h}$. There are about eight staffs for 12 patients in the morning shift and 7 in each evening and night shift. The mean age, proportion of male to female, presence of comorbid conditions, number of days of central venous cannulation (1267 vs. 1153), and number of days of mechanical ventilation (1559 vs. 1369) were comparable in pre- and postintervention phase [Table 1]. The baseline incidence of VAP in Phase 1 was $28.8(45 / 1559 \times 1000)$, and in Phase 3, the incidence of VAP increased to $35.1(48 / 1369 \times 1000)$, and this difference was not statistically significant. However, the incidence of
CLABSI was $7.9(10 / 1267 \times 1000)$ in Phase 1 and it decreased significantly to $1.7(2 / 1153 \times 1000)$ [Table 2 ]

Out of 41 staff nurses, 37 returned filled-in questionnaire. All felt motivated and agreed that classes were useful. The factors preventing them from the following bundles were lack of involvement of nurses during clinical rounds ( $n=20,54 \%)$, lack of materials $(n=12,32 \%)$, and lack of time to follow bundles $(n=5,13.5 \%)$. The staff nurses working in ICU remained the same throughout the study period.

\section{DISCUSSION}

Our study demonstrated a significant reduction in the incidence of CLABSI in the postintervention phase after extensive education and training of staff nurses on hand hygiene, VAP, and CLABSI bundles. However, it failed to demonstrate any significant reduction in the incidence of VAP, which actually increased in the postintervention phase.

Several authors have concluded that extensive training of nurses emphasizing infection control practices helps reduce the incidence of these infections. Cherifi et al., in a multicenter, quasi-experimental study, analyzed the impact of intervention based on process control and performance feedback to decrease CLABSI rates in five ICUs and concluded that external auditing and performance feedback resulted in reduction in rates of CLABSI. ${ }^{[3]}$ Righi et al. reported that implementation of a standardized approach to patient care helped reducing the risk of developing VAP. They implemented bundle of VAP prevention and selective digestive tract decontamination and found a significant reduction in the incidence of VAP in their ICU. ${ }^{[4]}$ Subramanian et al. emphasized on nurse-led education regarding VAP and VAP care bundles for training the nursing staff in ICU. They reported a significant reduction in VAP rates after intensive training of nursing staff. ${ }^{[2]}$

Al-Tawfiq et al. also found reduction in device-associated infection rates with the use of device-associated infection prevention bundles. Over the 7 years of data collection, they reported that infection prevention was efficient when bundles were followed after proper training. ${ }^{[5]}$ Ceballos et al. have also mentioned that when the infection control practices are nursing staff driven, better outcomes are seen in terms of reduction in the incidence of infection which ultimately cuts down the cost of health care also. ${ }^{[6]}$

However, as in our study, decrease in secondary sepsis in one aspect (CLABSI) and increase in secondary sepsis in other aspect (VAP) indicate that nursing education and training is not the only factor determining improvement in patient care. The causation seems to be multifactorial and emphasizing on good nursing care is just one aspect. In an observational study by Hamishehkar et al., the mean compliance for VAP care bundle was $36.5 \%$ and $41.2 \%$ in pre- and posteducation phase, respectively. They concluded that education alone is not effective in improving VAP bundle compliance and emphasized that the process of preaching the importance of 


\begin{tabular}{|c|c|c|c|}
\hline Parameter & Preintervention phase $(n=241)$ & Postintervention phase $(n=219)$ & $\boldsymbol{P}$ \\
\hline Mean age (years) & $44 \pm 11.29$ & $43 \pm 9.22$ & 0.3015 \\
\hline Number of male/female patients & $129 / 112$ & $116 / 103$ & 0.9256 \\
\hline Presence of comorbid condition $(n)$ & $154 / 241$ & $132 / 219$ & 0.4423 \\
\hline Total number of days of central venous cannulation & 1267 & 1153 & NA \\
\hline Total number of days of MV & 1559 & 1369 & NA \\
\hline
\end{tabular}

$* P<0.05$ is significant. NA: Not available; MV: Mechanical ventilation

\begin{tabular}{|c|c|c|c|c|c|c|c|}
\hline Year & Month & CVC days & CLABSI & CLABSI/1000 CVC days & $\begin{array}{l}\text { MV } \\
\text { days }\end{array}$ & VAP & VAP/1000 MV days \\
\hline 2015 & April & 165 & 1 & 6.06 & 230 & 5 & 21.74 \\
\hline 2015 & May & 215 & 3 & 13.95 & 286 & 8 & 27.97 \\
\hline 2015 & June & 248 & 1 & 4.03 & 264 & 6 & 22.73 \\
\hline 2015 & July & 273 & 4 & 14.65 & 311 & 12 & 38.59 \\
\hline 2015 & August & 229 & 0 & 0 & 232 & 9 & 38.79 \\
\hline 2015 & September & 137 & 1 & 7.29 & 236 & 5 & 21.19 \\
\hline Total & & 1267 & 10 & 7.89 & 1559 & 45 & 28.86 \\
\hline 2016 & April & 135 & 0 & 0 & 206 & 11 & 53.40 \\
\hline 2016 & May & 143 & 0 & 0 & 227 & 12 & 52.86 \\
\hline 2016 & June & 226 & 0 & 0 & 220 & 6 & 27.27 \\
\hline 2016 & July & 233 & 0 & 0 & 233 & 6 & 25.75 \\
\hline 2016 & August & 183 & 1 & 5.46 & 238 & 8 & 33.61 \\
\hline 2016 & September & 233 & 1 & 4.29 & 245 & 5 & 20.41 \\
\hline Total & & 1153 & 2 & 1.73 & 1369 & 48 & 35.06 \\
\hline$P$ & & & $0.0317^{*}$ & & $P$ & 0.3478 & \\
\hline
\end{tabular}

$* P<0.05$ is significant. VAP: Ventilator-associated pneumonia; CLABSI: Central line-associated bloodstream infection; CVC: Central venous catheter; MV: Mechanical ventilation

VAP care bundle should be continuous along with ongoing supervision in ICU. ${ }^{[7]}$ In another study by Jam Gatell et al., the training sessions for nurses did improve their knowledge of VAP care bundles and compliance with components of VAP care bundle, but this did not result in change in the incidence of VAP. However, they did observe a trend toward lower incidence of late VAP ( $>4$ days after intubation). ${ }^{[8]}$

In a systemic review by Jansson et al., eight studies did show a significant improvement in clinical outcome measured in terms of the length of ICU and hospital stay, decrease in the incidence of VAP, overall mortality, and costs after increasing the education of ICU personnel. They further concluded that multicenter, randomized, controlled, follow-up studies must be designed which study a universal method of outcome to evaluate the exact relationship between interventions such as nurse education and training and overall clinical outcomes. ${ }^{[9]}$

Nolan et al. suggested that increasing nurse accountability by the introduction of morbidity and mortality peer-review conferences (MMPRCs) which include presentation of history of the particular case, the overall clinical course, comorbidities associated, and compliance with VAP care bundle did reduce the incidence of VAP. They emphasized that MMPRC process should be considered for all the ICU indicators which involve nursing care to increase accountability of nursing staff which will lead to overall improved patient outcome. ${ }^{[10]}$

The study had few limitations, the most important being that the incidence of VAP and CLABSI does not directly relate to nurse education and knowledge. Furthermore, the questionnaire used for feedback is not a validated one although empty space left for anything new to be added by staff nurses.

\section{ConcLusion}

The intensive education and training of staff nurses about hand hygiene, CLABSI, and VAP bundles for a certain period does not lead to reduction in incidence of VAP. Hence, the education, bedside skill demonstration, auditing, and feedback should be done continuously. However, as CLABSI incidence decreased significantly, we need to look for other factors which are responsible for increase in the incidence of VAP apart from nursing practices.

\section{Financial support and sponsorship}

Nil.

\section{Conflicts of interest}

There are no conflicts of interest. 


\section{References}

1. Tang HJ, Chao CM, Leung PO, Lai CC. Achieving "zero" CLABSI and VAP after sequential implementation of central line bundle and ventilator bundle. Infect Control Hosp Epidemiol 2015;36:365-6.

2. Subramanian P, Choy KL, Gobal SV, Mansor M, Ng KH. Impact of education on ventilator-associated pneumonia in the Intensive Care Unit. Singapore Med J 2013;54:281-4.

3. Cherifi S, Gerard M, Arias S, Byl B. A multicenter quasi-experimental study: Impact of a central line infection control program using auditing and performance feedback in five Belgian Intensive Care Units. Antimicrob Resist Infect Control 2013;2:33.

4. Righi E, Aggazzotti G, Ferrari E, Giovanardi C, Busani S, Rinaldi L, et al. Trends in ventilator-associated pneumonia: Impact of a ventilator care bundle in an Italian tertiary care hospital Intensive Care Unit. Am J Infect Control 2014;42:1312-6.

5. Al-Tawfiq JA, Amalraj A, Memish ZA. Reduction and surveillance of device-associated infections in adult Intensive Care Units at a
Saudi Arabian hospital, 2004-2011. Int J Infect Dis 2013;17:e1207-11.

6. Ceballos K, Waterman K, Hulett T, Makic MB. Nurse-driven quality improvement interventions to reduce hospital-acquired infection in the NICU. Adv Neonatal Care 2013;13:154-63.

7. Hamishehkar H, Vahidinezhad M, Mashayekhi SO, Asgharian P, Hassankhani $\mathrm{H}$, Mahmoodpoor A, et al. Education alone is not enough in ventilator associated pneumonia care bundle compliance. J Res Pharm Pract 2014;3:51-5.

8. Jam Gatell MR, Santé Roig M, Hernández Vian Ó, Carrillo Santín E, Turégano Duaso C, Fernández Moreno I, et al. Assessment of a training programme for the prevention of ventilator-associated pneumonia. Nurs Crit Care 2012;17:285-92.

9. Jansson M, Kääriäinen M, Kyngäs H. Effectiveness of educational programmes in preventing ventilator-associated pneumonia: A systematic review. J Hosp Infect 2013;84:206-14.

10. Nolan SW, Burkard JF, Clark MJ, Davidson JE, Agan DL. Effect of morbidity and mortality peer review on nurse accountability and ventilator-associated pneumonia rates. J Nurs Adm 2010;40:374-83.

\section{Annexure 1: ICU Nurses' Feedback Form}

1. Are you satisfied with the content of classes and demonstrations of infection prevention in ICU?

Yes/No If no, suggest changes.

2. What is the most common faced by you in following VAP bundle for your patient?

a) Lack of the materials needed (mouthwash, oral care kit, gloves, suction catheter)

b) Lack of time to follow VAP bundle

c) Lack of cooperation and guidance by senior staff and doctors

d) No doctor discusses patient details with you, so you feel disinterested.

3. In your opinion, what is the most common factor leading to secondary infections in ICU?

a) Inappropriate suctioning technique by staff nurses

b) Inappropriate hand hygiene by doctors and staff in ICU

c) Lack of cleanliness in ICU.

d) Lack of support and motivation by senior staff of ICU

e) Any other.

f) All of the above

4. After attending the classes on infection prevention, do you feel motivated to follow VAP and CLABSI bundles for your patient?

5. Will you own your patient in ICU and prevent anyone (whether senior or junior) from touching your patient and his surroundings without performing proper hand hygiene? 